Akreditasi KEMENRISTEKDIKTI, Nomor: 148/M/KPT/2020
http://iurnal.stkippersada.ac.id/iurnal/index.php/VoX

\title{
STUDI EKSPLORATIF PENERAPAN PROGRAM SEKOLAH ADIWIYATA DI SMPN 3 SINTANG PADA MASA PANDEMI COVID-19
}

\author{
Rachmi Afriani ${ }^{1}$, \& Hendra Setiawan ${ }^{2}$ \\ ${ }^{1,2}$ Program Studi Pendidikan Biologi FKIP Universitas Kapuas Sintang \\ Email: rachmiafriani@yahoo.com ${ }^{1}$, hendra_setiawan09@yahoo.com ${ }^{2}$
}

\section{INFO ARTIKEL}

Riwayat Artikel:

Menerima : 17 September 2021

Revisi : 27 Oktober 2021

Diterima : 11 Nopember 2021

\section{Kata Kunci:}

Sekolah Adiwiyata, Pandemi

Covid-19, SMPN 3 Sintang
Keywords:

Adiwiyata green school, Covid-19 pandemic, SMPN 3 Sintang

\section{Korespondensi:}

Rachmi Afriani

Prodi Pendidikan Biologi FKIP

Universitas Kapuas Sintang

Email:

rachmiafriani@yahoo.com

\section{ABSTRAK}

Pandemi covid-19 mengakibatkan pelaksanaan program Adiwiyata menjadi tidak efektif. Penelitian ini bertujuan untuk mengetahui implementasi program sekolah Adiwiyata di SMPN 3 Sintang selama masa pandemi Covid-19. Metode penelitian ini adalah kualitatif deskriptif. Penelitian ini dilaksanakan dari bulan Februari- Agustus 2021. Pengambilan data menggunana metode triangulasi wawancara, observasi dan dokumentasi. Pemilihan sekolah mitra menggunakan teknik purposive sampling. Responden yang dilibatkan dalam penelitian ini antara lain stakeholder dari DLH, kepala sekolah mitra, waka bidang kurikulum dan ketua program sekolah Adiwiyata. Analisis data dilakukan secara deskriptif. Hasil penelitian ini menunjukkan ada dukungan DLH Kabupaten Sintang terhadap penghargaan Adiwiyata namun karena dampak Pandemi Covid-19 menyebakan kegiatan pembinaan tidak dapat dilakukan maksimal. SMPN 3 Sintang saat ini belum menggunakan pedoman Adiwiyata terbaru yaitu Permen LHK No. 53 Tahun 2019 tentang Penghargaan Adiwiyata, tetapi masih menerapkan berdasarkan Permen LH No. 5 Tahun 2013 tentang Pedoman Pelaksanaan Program Adiwiyata. Namun demikian, berdasarkan hasil wawancara dan observasi kondisi lingkungan di SMPN 3 Sintang sudah sangat baik, memegang tinggi nilai konservasi berbasis kekayaan local dan sudah ada kesepakatan bersama untuk tetap menjaga lingkungan. Hal yang masih kurang adalah terkait dengan konservasi air dan energi listrik yang masih baru untuk wilayah Kabupaten Sintang.

\section{ABSTRACT}

Covid-19 Pandemic was affected all element in Adiwiyata green school program. The aim of this research was to know the implementation of Adiwiyata green school in SMPN 3 Sintang during Pandemic Covid-19. Qualitative descriptive was used through triangulation method. It was done on February to August 2021. Data collecting used interview, observation and documentation. Partner school was selected through purposive sampling. The key informants consist of Environmental Agency of Sintang Districts stakeholder, SMPN 3 Sintang's Principal, vice principal in academic affairs, and PIC of Adiwiyata green school program of SMPN 3 Sintang. Data analysis through qualitative descriptive. The results of this research shows that there are a fully support from Environmental Agency of Sintang District in the development of Adiwiyata green school program. However, Covid-19 pandemic affected almost all of environmental program in this district. Based on interview resul SMPN 3 Sintang is still used manual of Permen LH No. 5 Tahun 2013 about Manual of Adiwiyata Program. Nevertheless, central government was already publish new manual of Adiwiyata program with Permen LHK No. 53 Tahun 2019 about Adiwiyata award. The observation results shows that SMPN 3 Sintang environment is in very good condition with high local wisdom values. Minus point of Adiwiyata green school program in SMPN 3 Sintang is that water and energy conservation which is still rare in Sintang District in general. 


\section{PENDAHULUAN}

Sekolah Adiwiyata adalah suatu program yang berpusat pada sekolah untuk mengelola lingkungannya dengan gerakan peduli dan berbudaya lingkungan dengan melibatkan seluruh warga sekolah secara partisipatif (Permen LHK, 2019). Program Sekolah Adiwiyata yang ada saat ini merupakan program yang terus berkembang sejak dicetuskan pada tahun 1996. Saat ini program Adiwiyata telah memegang peran penting dalam pengelolaan lingkungan di sekolah. Sekolah Adiwiyata mendukung pengelolaan lingkungan yang memberikan konsep cinta lingkungan secara komprehensif. Kegiatan sekolah adiwiyata di sekolah meliputi semua keagiatan pengembangan kebijakan berwawasan lingkungan, pengelolaan kurikulum berwawasan lingkungan, pelaksanaan kegiatan lingkungan berbasis partisipatif dan pengelolaan sarana dan prasarana lingkungan (Setiawan et al, 2019).

Pemerintah Republik Indonesia melalui Kementerian Lingkungan Hidup dan Kehutanan pada tahun 2019 memberikan perhatian penuh terhadap pengelolaan lingkungan di sekolah dengan memberikan pembaharuan terhadap pedoman pelaksanaan program sekolah Adiwiyata dengan menyesuaikan dengan kondisi yang ada saat ini. Pemerintah mengeluarkan Peraturan Menteri Lingkungan Hidup dan Kehutanan Republik Indonesia Nomor 53 Tahun 2019 tentang Penghargaan Adiwiyata yang menggantikan Peraturan Menteri Lingkungan Hidup dan Kehutanan Republik Indonesia Nomor 5 Tahun 2013 tentang Pedoman Pelaksanaan Program
Adiwiyata. Perubahan mendasar pada kedua peraturan ini pada konsep konservasi energi yang diterapkan di sekolah yang sejalan dengan konsep pembangunan berkelanjutan yang dicetuskan oleh Perserikatan Bangsa-bangsa (PBB).

Pandemi Covid-19 yang mulai mewabah pada awal tahun 2020 menyebabkan perubahan yang sangat mendasar pada semua aspek kehidupan manusia, tidak terkecuali pengelolaan program sekolah Adiwiyata. Penerapan Pembelajaran Jarak Jauh (PJJ) yang menyebabkan tidak adanya aktivitas di sekolah menyebabkan program sekolah Adiwiyata tidak berjalan dengan efektif. Hal ini disebabkan oleh banyak faktor yang saling berinteraksi. Pelaksanaan pelonggaran kegiatan di sekolah menyebabkan mulai adanya aktivitas di sekolah sehingga pengelolaan lingkungan sekolah mulai dilaksanakan kembali.

SMPN 3 Sintang yang merupakan salah satu pionir sekolah Adiwiyata di Kabupaten Sintang tidak terlepas dari dampak pandemic Covid-19. Saat ini, SMPN 3 Sintang merupakan Sekolah Adiwiyata tingkat Provinsi yang didapat pada tahun 2016.

Penelitian ini bertujuan untuk mengetahui implementasi program sekolah Adiwiyata di SMPN 3 Sintang selama masa pandemi Covid-19. Assesmen secara menyeluruh terhadap penerapan sekolah Adiwiyata di SMPN 3 Sintang diharpakan dapat dijadikan dasar dalam pengelolaan sekolah Adiwiyata di Kabupaten Sintang secara umum pasca pandemi kedepannya. 


\section{METODE PENELITIAN}

Penelitian ini dilaksanakan dari bulan Februrari-Agustus 2021 di SMPN 3 Sintang. Metode penelitian ini adalah kualitatif deskriptif (Setiawan et al, 2019; Sumarni et al, 2020). Penelitian dilaksanakan pada masa Pandemi Covid-19 dengan menerapkan protocol Kesehatan ketat dan tidak dalam masa penguncian (lock down). Pengambilan data menggunana metode triangulasi menggunakan wawancara, observasi dan dokumentasi (Carter et al, 2014). Pemilihan sekolah mitra dilakukan menggunakan teknik purposive sampling dengan alasan pemilihan adalah Sekolah yang berada di Kota Sintang dan berpredikat sekolah Adiwiyata minimal tingkat Provinsi. SMPN 3 Sintang dipilih karena merupakan Sekolah Adiwiyata tingkat Provinsi dan terletak di pusat kota Sintang dan dianggap sebagai salah satu sekolah yang paling ideal dalam penerapan Program Sekolah Adiwiyata.

Responden wawancara yang dilibatkan dalam penelitian ini antara lain stakeholder dari Dinas Lingkungan Hidup yang mengelola program sekolah Adiwiyata, kepala SMPN 3 Sintang, Wakil Kepala Sekolah Bidang Akademik dam ketua program sekolah Adiwiyata. Pertanyaan yang digunakan adalah terkait dengan penghargaan Adiwiyata yaitu Gerakan Peduli dan Berbudaya Lingkungan Hidup di Sekolah (PBLHS) antara lain tentang perencanaan Gerakan PBLHS dalam dokumen evaluasi diri sekolah (EDS), kurikulum, dan Rencana Pelaksanaan Pembelajaran (RPP) serta stakeholder penyusunnya; pelaksanaan Gerakan PBLHS mulai dari sarana prasarana peduli lingkungan, pengelolaan sampah, penanaman dan pemeliharaan taman, konservasi air dan energi, inovasi sekolah, keterlibatan masyarakat, jejaring masyarakat serta publikasi PBLHS; dan yang terakhir pemantauan dan evaluasi Gerakan PBLHS.

Validasai data hasil wawancara dilakukan dengan melakukan observasi dan dokumentasi di SMPN 3 Sintang. Observasi dilakukan dengan pengamatan langsung di lingkungan SMPN 3 Sintang dengan didukung data foto dan video. Dokumentasi digunakan untuk memastikan data yang disampaikan benar-benar terdokumentasikan oleh sekolah melalui dokumen Visi Misi Sekolah, EDS, Kurikulum, RPP, dan dokumen pendukung lainnya. Analisis data dilakukan secara deskriptif kualitatif kemudian data disampaikan dalam bentuk deskripsi, tabel, gambar, grafik, dan lain sebagainya.

\section{HASIL DAN PEMBAHASAN}

Kebijakan Sekolah Adiwiyata pada Masa Pandemi Covid-19 di Kabupaten Sintang

Pandemi Covid-19 menyebabkan perubahan dalam tatanan social masyarakat termasuk dalam penerapan program Sekolah Adiwiyata di Kabupaten Sintang. Program Sekolah Adiwiyata di Kabupaten Sintang di bawah koordinasi Bidang Pengendalian Pencemaran Kerusakan Lingkungan dan Peningkatan Kapasitas Lingkungan Hidup (PPKLPKLH) Dinas Lingkungan Hidup Kabupaten Sintang yang mana saat ini dikepalai oleh Joanna Fransisca, B.P. S.Hut. Dalam wawancara yang dilakukan kepada Ibu Joana Fransisca B.P., S.Hut pada tanggal 25 Mei 2021, menyampaikan bahwa Pemerintah 
Daerah dalam hal ini Dinas Lingkungan Hidup Kabupaten Sintang memiliki prioritas yang lebih penting terkait penanganan Pandemi Covid-19 dari sisi Kesehatan dan pemulihan kondisi ekonomi sehingga program lainnya menjadi sedikit terabaikan. Hal ini dapat dilihat dari bahwa pada tahun 2019 (sebelum pandemi Covid-19) dana yang dianggarkan untuk Program Peningkatan Kualitas dan Akses Informasi Sumber Daya Alam dan Lingkungan Hidup (Bidang PPKLPKLH) sebesar Rp. 63.846.900 (Enam puluh tiga juta delapan ratus empat puluh enam ribu sembilan ratus rupiah) yang salah satu diantaranya digunakan untuk penyelenggaraan pemilihan calon sekolah adiwiyata tingkat Kabupaten, Provinsi, Nasional, dan Mandiri serta penyelenggaraan program pembinaan terhadap calon sekolah Adiwiyata di Kabupaten Sintang dengan target realisasinya yaitu terdapat 5 sekolah yang mendapat penghargaan sekolah Adiwiyata Kabupaten, Provinsi, Nasional, dan Mandiri serta 5 calon sekolah Adiwiyata tingkat Kabupaten, Provinsi, Nasional, dan Mandiri (Anonim, 2020).

Namun dampak pandemi yang mereduksi Anggaran Pendapatan Belanja Daerah (APBD) di seluruh Indonesia menyebabkan berkurangnya anggaran yang tidak berkaitan langsung dengan penanggulangan Pandemi hampir 50\%, termasuk salah satunya di Kabupaten Sintang. Pengurangan nilai pendapatan asli daerah (PAD) yang menyebabkan komposisi APBD berubah derastis. Selain itu, kebijakan yang diarahkan dari Kementerian Dalam Negeri yang mengharuskan daerah menyiapkan dana cukup besar dari total APBD untuk keperluan penanggulangan Pandemi menyebabkan program di luar kepentingan tersebut semakin tersisihkan.

Walaupun dengan segala keterbatasan dana dan sumber daya manusia selama Pandemi Covid-19, Pemerintah Daerah Kabupaten Sintang melalui Badan PPKLPKLH Dinas Lingkungan Hidup tetap memberikan dukungan kepada sekolah-sekolah yang masih menjalankan program Sekolah Adiwiyata di Kabupaten Sintang. Dukungan tersebut antara lain dengan memberikan bimbingan dan arahan yang dilakukan melalui media telepon baik menggunakan aplikasi pesan (WhatsApp) atau melalui telepon secara langsung.

Hubungan baik yang sudah dibangun antara Badan PPKLPKLH Dinas Lingkungan Hidup Kabupaten Sintang masih terus di jaga agar pada saat Pandemi sudah dapat dikendalikan dan proses pembelajaran sudah dilakukan di sekolah secara langsung, program Adiwiyata yang berfokus pada pemeliharaan lingkungan sekolah dapat diteruskan dengan baik. Hubungan baik ini merupakan modal dasar dalam membangun jejaring organisasi yang sama-sama peduli terhadap perlindungan lingkungan (Sugianto et al., 2019).

\section{Kondisi Lingkungan SMPN 3 Sintang}

SMPN 3 Sintang merupakan salah satu Sekolah Menengah Pertama yang ada di Kota Sintang dan terletak di Jalan Y.C. Oevang Oeray, Desa Baning Kota, Kecamatan Sintang, Kabupaten Sintang. Sekolah ini dibangun di atas tanah yang memiliki kontur miring. Pada beberapa titik, tingkat kemiringan diperkirakan 
dapat mencapai $60^{\circ}$ yang mana menunjukkan bahwa tanah tersebut dapat dikategorikan sangat curam dan memiliki resiko tanah longsor (Gambar 1 dan 2).

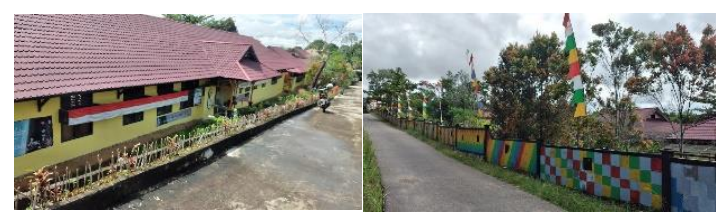

Gambar 1. Landscape SMPN 3 Sintang

(Dokumentasi Pribadi, 2021).

Namun demikian, dengan pengelolaan landscape SMPN 3 Sintang yang dilakukan dengan pendekatan alami maka kontur tanah yang bertingkat ini tidak dilakukan pengerukan yang dapat merusak ekosistem melainkan dengan melakukan penghijauan pada kontur tersebut sehingga akar tumbuhan tersebut dapat mengikat air permukaan yang mengikis tanah dan menghindarkan dari resiko tanah longsor.

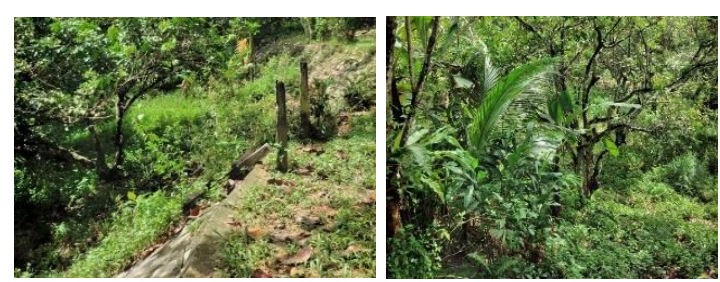

Gambar 2. Lereng di SMPN 3 Sintang yang ditanami tumbuhan sebagai pelindung erosi

(Dokumentasi Pribadi, 2021).

\section{SMPN 3 Sintang memanfaatkan} tumbuhan lokal berdaya guna dalam upaya penghijauan di Sekolah. Penanaman tumbuhan local ini memberikan dampak yang baik terhadap ekosistem sekitar. Pemilihan jenis tumbuhan yang salah malah dapat berdampak buruk, misalnya dengan secara tidak sengaja menanamkan tumbuhan infasif (Invasive species) ke dalam lingkungan sekolah. Invasive species adalah jenis tumbuhan/hewan yang tidak berasal dari tempat tersebut namun kemudian dipindahkan secara sengaja atau tidak sengaja ke dalam suatu ekosistem yang baru dan sangat mendukung pertumbuhan spesies tersebut sehingga menyebabkan spesies alami pada ekosistem tersebut menjadi kalah bersaing (Rai \& Singh, 2020).

Umumnya invasive species memiliki tampilan yang menarik terutama pada bunga sehingga secara sengaja ditanam oleh masyarakat yang tanpa disadari menjadi pengganggu bagi tanaman asli daerah tersebut. Namun demikian SMPN 3 Sintang telah dengan bijak memilih jenis tumbuhan penghijauan yang berasal dari tumbuhan local. Berdasarkan hasil observasi yang dilakukan pada tanggal 26 Agustus 2021, diketahui beberapa jenis tumbuhan lokal yang ditanami di lingkungan SMPN 3 Sintang seperti pada Tabel 1.

Tabel 1. Data Tumbuhan Lokal di SMPN 3 Sintang

\begin{tabular}{|c|c|c|c|}
\hline No & $\begin{array}{l}\text { Nama } \\
\text { umum }\end{array}$ & Nama latin & Kategori \\
\hline 1 & Rambutan & $\begin{array}{l}\text { Nephelim } \\
\text { lapaceum }\end{array}$ & $\begin{array}{l}\text { Tumbuhan } \\
\text { buah }\end{array}$ \\
\hline 2 & Kelapa & Cocos nucifera & $\begin{array}{l}\text { Tumbuhan } \\
\text { buah }\end{array}$ \\
\hline 3 & Mangga & $\begin{array}{l}\text { Mangifera } \\
\text { indica }\end{array}$ & $\begin{array}{l}\text { Tumbuhan } \\
\text { buah \& } \\
\text { peneduh }\end{array}$ \\
\hline 4 & Pisang & $\begin{array}{l}\text { Musa } \\
\text { paradisiaca }\end{array}$ & $\begin{array}{l}\text { Tumbuhan } \\
\text { buah }\end{array}$ \\
\hline 5 & Petai cina & $\begin{array}{l}\text { Laucaena } \\
\text { leucocephala }\end{array}$ & $\begin{array}{l}\text { Tumbuhan } \\
\text { buah }\end{array}$ \\
\hline 6 & Srikaya & $\begin{array}{l}\text { Annona } \\
\text { squamosa }\end{array}$ & $\begin{array}{l}\text { Tumbuhan } \\
\text { buah }\end{array}$ \\
\hline 7 & $\begin{array}{l}\text { Pucuk } \\
\text { merah }\end{array}$ & $\begin{array}{l}\text { Syzgium } \\
\text { paniculatum }\end{array}$ & $\begin{array}{l}\text { Tumbuhan } \\
\text { hias \& } \\
\text { peneduh }\end{array}$ \\
\hline 8 & Pinang & Areca catechu & $\begin{array}{l}\text { Tumbuhan } \\
\text { buah }\end{array}$ \\
\hline 9 & Jambu bol & $\begin{array}{l}\text { Syzgium } \\
\text { malaccense }\end{array}$ & $\begin{array}{l}\text { Tumbuhan } \\
\text { buah }\end{array}$ \\
\hline 10 & Serai & $\begin{array}{l}\text { Cymbopogon } \\
\text { citratus }\end{array}$ & $\begin{array}{l}\text { Tumbuhan } \\
\text { obat \& } \\
\text { rempah }\end{array}$ \\
\hline
\end{tabular}

Sumber : Hasil Observasi, 2021 
Penanaman tumbuhan berdaya guna memberikan manfaat secara langsung bagi warga sekolah. Berdasarkan hasil wawancara kepada Guru Koordinator Sekolah Adiwiyata SMPN 3 Sintang Ibu Sri Hidayah, S.Ag., alasan penanaman tumbuhan local berdaya guna, terutama tumbuhan buah dikarenakan warga sekolah dapat memanfaatkan langsung hasil buah tersebut dan memberikan suatu kepuasan tersendiri oleh warga sekolah yang menanamnya. Hal ini sejalan dengan hasil penelitian tentang sekolah Adiwiyata di SDN 7 Sintang yang mana juga memberikan alasan bahwa dengan menanam langsung tumbuhan bermanfaat (dalam hal ini tumbuhan buah) pada saat panen buahnya akan memberikan rasa puas dan bangga akan pencapaian tersebut (Setiawan et al, 2020).

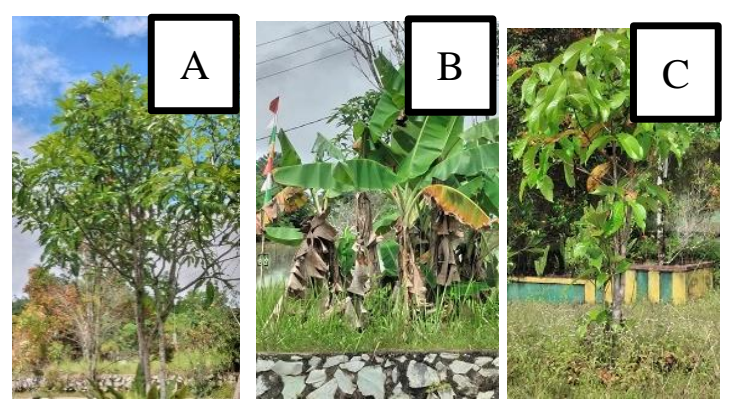

Gambar 3. Tumbuhan buah lokal di lingkungan SMPN 3 Sintang

Keterangan : A) Mangga; B) Pisang; C) Jambu Bol

(Dokumentasi Pribadi, 2021)

Secara keseluruhan, kondisi lingkungan SMPN 3 Sintang selalu terlihat rapi dan bersih. Hal ini dapat dilihat dari tidak adanya sampah yang berserakan dan tumpukan sampah di lingkungan SMPN 3 Sintang. Walaupun aktifitas warga sekolah hampir tidak ada, namun aktifitas warga sekitar juga berpengaruh terhadap kebersihan sekolah. Namun karena adanya kesadaran dari warga sekitar untuk menjaga kebersihan lingkungannya menyebabkan tidak adanya sampah yang dapat merusak lingkungan.

Selain kondisi sampah, kondisi lingkungan sekolah tidak dapat dipungkiri bahwa terdapat rumput/tumbuhan liar yang tinggi dan seperti kurang terawatt. Hal ini tentu bukan merupakan suatu pembiaran yang berasal dari warga sekolah, namun karena kondisi pandemi yang tidak memungkinkan pengelolaan lingkungan sekolah secara optimal (Setiawan, 2021).

Berdasarkan hasil wawancara kepada Kepala SMPN 3 Sintang, Ibu Raliti, S.Pd, menyampaikan bahwa selama pandemi Covid19 berlangsung, para guru dan staf tetap diwajibkan masuk secara bergiliran. Sebelum pandemi, tanggung jawab kebersihan lingkungan dilakukan secara bersama oleh Guru, siswa dan petugas kebersihan, namun saat pandemi hanya dilakukan oleh petugas Kebersihan.

Program Sekolah Adiwiyata memiliki peran penting dalam pengelolaan lingkungan hidup di SMPN 3 Sintang. Program ini yang telah dilaksanakan di SMPN 3 Sintang sejak tahun 2016 telah mengakar baik di lingkungan warga sekolah. Peran serta semua pihak, baik Kepala Sekolah, dukungan Komite Sekolah, para Guru, Tenaga kebersihan, serta para murid sangat penting dalam menjaga lingkungan secara bersama-sama. Kerja secara partisipatif inilah yang menjaga lingkungan SMPN 3 Sintang tetap bersih, rapi, hijau, dengan mengedepankan tumbuhan local. Selain itu, berdasarkan hasil wawancara kepada Kepala 
Sekolah, selain dukungan warga sekolah, terdapat berbagai pihak yang mendukung pengembangan program Sekolah Adiwiyata antara lain Dinas Lingkungan Hidup Kabupaten Sintang dengan bantuan alat pengelolaa sampah (composting), Dinas Lingkungan Hidup Provinsi Kalimantan Barat (pada saat pemberian penghargaan Sekolah Adiwiyata tingkat Provinsi) memberikan dukungan pengembangan program.

Namun demikian, pihak sekolah juga menyadari bahwa dengan adanya Program Sekolah Adiwiyata ini memerlukan usaha lebih dari semua warga sekolah untuk dapat memenuhi semua standar yang ada sehingga akan lebih baik apabila usaha warga sekolah ini dapat diberikan apresiasi berupa dana pengembangan yang dapat disisihkan dari APBD Kabupaten atau Provinsi agar dapat memberikan semangat bagi sekolah untuk berlomba-lomba mengelola lingkungan sekolah sesuai panduan program Sekolah Adiwiyata. Keuntungan ekonomi dapat memberikan motivasi tinggi dalam pengelolaan lingkungan pada masa pandemi covid-19 (Intan et al, 2021).

\section{Pelaksanaan Program Adiwiyata di SMPN 3 Sintang}

Pelaksanaan Program Adiwiyata di SMPN 3 Sintang tidak terlepas dari pedoman Sekolah Adiwiyata yang dikeluarkan oleh Kementerian Lingkungan Hidup Republik Indonesia. Pedoman yang digunakan oleh SMPN 3 Sintang pada saat mengikuti Program Sekolah Adiwiyata adalah Peraturan Menteri Lingkungan Hidup Nomor 5 Tahun 2013 tentang Pedoman Pelaksanaan Program Adiwiyata. Dalam pedoman ini, program adiwiyata memiliki 4 (empat) komponen utama yaitu 1) Kebijakan Sekolah Berwawasan Lingkungan; 2) Kurikulum Berwawasan Lingkungan; 3) Kegiatan Lingkungan Berbasis Partisipatif; dan 4) Pengelolaan Sarana \& Prasarana Pengelola Lingkungan. Keempat komponen utama ini yang menjadi dasar pelaksanaan program Adiwiyata di SMPN 3 Sintang.

Kebijakan sekolah berwawasan lingkungan diterjemahkan oleh SMPN 3 Sintang dalam bentuk Visi-Misi Sekolah yang mendukung pengelolaan lingkungan (Sugianto et al, 2019). Visi SMPN 3 Sintang yaitu Terbentuknya Manusia yang Beriman, Bertaqwa, Berbudaya, Berprestasi, dan Berwawasan Lingkungan, Visi ini kemudian dijabarkan ke dalam misi-misi antara lain 1) Mewujudkan kurikulum yang berkarakter dan berbudaya bangsa; 2) Mewujudkan proses pembelajaran efektif dan efisien yang dititikberatkan pada proses pembelajaran scientific; 3) Mewujudkan tenaga pendidik dan tenaga kependidikan yang memiliki kompetensi dan kualifikasi yang dipersyaratkan standar nasional Pendidikan; 4) Mewujudkan manajemen sekolah yang efektif dan efisien; 5) Mewujudkan sumber daya manusia yang berkualitas dalam bidang akademik dan nonakademik sehingga tercipta sekolah yang bermutu; 6) Mewujudkan prasarana dan sarana Pendidikan yang sesuai standar; 7) Mewujudkan lulusan yang berakhlak mulia, cerdas, terampil, kreatif; 8) Mewujudkan penataan kebersihan dan keindahan lingkungan 
sekolah sesuai standar. Misi pengelolaan lingkungan tertuang dalam misi ke- 8 yang menekankan pada kebersihan dan keindahan lingkungan. Kebijakan lingkungan dalam bentuk visi-misi sekolah ini merupakan dasar bagi warga sekolah di dalam pengembangan kegiatan peduli lingkungan.

Selain itu, kebijakan lingkungan di aplikasikan dengan mendelegasikan tanggung jawab kebersihan kepada semua warga sekolah (Aksiadi \& Gumilar, 2020). Para murid diwajibkan untuk membersihkan kelas dan lingkungan setiap hari sebelum masuk kelas. Para guru wajib mendampingi murid selama melakukan kegiatan kebersihan. Kantin sekolah saat melakukan operasional wajib menjaga kebersihan dan selain itu kemasan plastic (kantong) yang digunakan sekali pakai dilarang penggunaannya di kantin sekolah (hasil wawancara kepada Kepala Sekolah).

Selama masa pandemi, walaupun murid tidak melakukan proses pembelajaran tatap muka langsung di kelas, guru dan tenaga kependidikan tetap wajib masuk secara bergiliran dengan memperhatikan kondisi Covid daerah dan menerapkan protokol Kesehatan ketat. Guru dan tenaga kependidikan ini lah yang berperan besar dalam menjaga lingkungan sekolah. Hal ini muncul karena kesadaran bersama bahwa lingkungan sekolah harus senantiasa bersih sehingga memberikan suasana yang nyaman untuk melakukan aktivitas di sekolah.

Penerapan kurikulum berwawasan lingkungan di SMPN 3 Sintang dilakukan secara komprehensif di semua mata pelajaran yang ada dengan menanamkan nilai dan budaya cinta lingkungan hidup. Berdasarkan hasil wawancara kepada Wakil Kepala Sekolah Bidang Kurikulum Pak Sutomo, S.Pd.Kn menyampaikan bahwa pengembangan kurikulum berwawasan lingkungan yang diterapkan di SMPN 3 Sintang dilakukan secara mandiri oleh guru mata pelajaran dengan bimbingan dari bidang kurikulum dan Kepala Sekolah. Selain itu, terdapat mata pelajaran khusus yang terkait dengan kurikulum berwawasan lingkungan ini yaitu mata pelajaran Pendidikan Lingkungan. Isi materi pelajaran ini membahas tentang teori dan praktik pengelolaan lingkungan yang baik dan dapat dilakukan oleh murid SMP.

Pada saat pandemi Covid-19, penerapan kurikulum berwawasan lingkungan sedikit terkendala karena media penyampaian pembelajaran yang pada umumnya menggunakan media WhatsApp dan Google Classroom (asinkron) sehingga pesan cinta lingkungan yang disampaikan oleh guru tidak langsung diterima oleh siswa yang berbeda pada saat sebelum pandemi. Namun demikian, kreatifitas Guru sangat dituntut dalam menghadapi tantangan proses pembelajaran yang terjadi di masa pandemi. Guru dituntut dapat memilih media yang tepat dalam menyampaikan materi tertentu agar pesan yang ingin disampaikan tetap dapat diterima murid dengan baik.

Pelaksanaan Kegiatan Lingkungan berbasis partisipatif pada saat sebelum pandemi di SMPN 3 Sintang dilakukan dengan baik. Hal ini dapat dilihat dari aktifitas siswa yang digambarkan oleh Kepala Sekolah, sangat aktif dalam mengelola lingkungannya. Para Guru 
dan siswa membawa bibit tanaman lokal dari rumah yang kemudian di tanam di lingkungan sekolah. Lokasi penanaman tanaman diatur sedemikian rupa agar tetap memiliki nilai estetika. Selain para warga sekolah, masyarakat sekitar serta orang tua/wali murid juga memiliki peran dalam menjaga lingkungan sekolah. Masyarakat sekitar secara inisiatif juga membantu pembersihan saluran drainase yang berasal dari rumah masing-masing yang dapat berdampak ke lingkungan sekolah. Hal ini dikarenakan kontur lingkungan SMPN 3 Sintang yang berbukit dan di bagian atas masih terdapat perumahan masyarakat yang dapat berdampak ke sekolah. Orang tua/wali murid memberikan dukungan dalam pengelolaan lingkungan sekolah dengan mendukung anaknya untuk senantiasa memiliki rasa cinta lingkungan baik di rumah maupun di sekolah.

Pelaksanaan kegiatan lingkungan berbasis partisipatif selama masa pandemi Covid-19 secara otomatis terganggu. Tidak adanya aktifitas optimal di sekolah serta larangan berkerumun yang dapat menyebabkan penyebaran virus menyebabkan tidak ada dilaksanakannya kegiatan lingkungan berbasis partisipatif. Namun demikian, kebijakan yang dikeluarkan oleh Kepala SMPN 3 Sintang dalam pengelolaan lingkungan sepenuhnya kepada Guru piket dan tenaga kebersihan sekolah.

Pengelolaan sarana dan prasarana penunjang lingkungan pada saat sebelum pandemi, berdasarkan hasil wawancara kepada Koordinator Sekolah Adiwiyata dilakukan dengan baik. Pembersihan fasilitas toilet, tong sampah, alat kebersihan dan lainnya dilakukan dengan baik oleh semua warga sekolah. Selain itu, pihak sekolah juga memiliki tong air yang digunakan untuk menampung air hujan dan air sumur untuk keperluan di Sekolah. Penempatan tong air yang diberikan penyangga kemudian pada bagian bawah diletakan tanaman kecil dalam pot agar apabila air tong penuh dan meluap dapat digunakan untuk menyiram tanaman di dalam pot. Selain dari fasilitas lingkungan yang ada, peran serta hasil prakarya siswa juga mendukung penyediaan sarana penunjang pengelolaan lingkungan di sekolah, antara lain pembuatan sapu lidi, pembuatan penghapus papan tulis, pembuatan tong sampah dari bahan bekas, dan lain-lain. Namun pada saat pandemi, semua upaya pengelolaan sarana dan prasarana penunjang lingkungan dilakukan oleh petugas kebersihan yang menyebabkan bertambahnya beban pekerjaan dibandingkan sebelum pandemi.

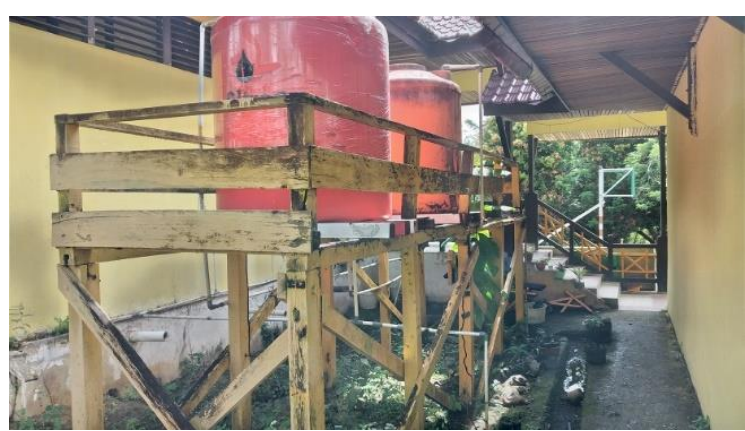

Gambar 4. Tata letak tong air yang di bawahnya diletakan tanaman dalam pot (Dokumentasi pribadi, 2021)

Perkembangan dan perubahan yang terjadi secara terus menerus dalam pengelolaan lingkungan menuntut adanya pembaharuan dalam pedoman sekolah Adiwiyata. Pedoman Adiwiyata yang dikeluarkan oleh Kementerian Lingkungan Hidup pada Tahun 2013 kemudian 
di revisi dan dikeluarkan Peraturan Menteri Lingkungan Hidup dan Kehutanan Nomor 53

Tahun 2019 tentang Penghargaan Adiwiyata.

Pada peraturan yang baru ini tidak menyebutkan secara spesifik tentang komponen Adiwiyata. Analisis terhadap peraturan ini diketahui bahwa esensi dari peraturan yang baru ini masih sama dengan pedoman Adiwiyata tahun 2013, namun, dengan penambahan indikator Konservasi Energi dan Konservasi Air. Penerapan peraturan baru tentang Adiwiyata ini masih sangat belum efektif karena mendapat dampak Pandemi Covid-19 yang mewabah sejak awal tahun 2020. SMPN 3 Sintang sendiri menyadari bahwa mereka belum menerapkan peraturan tentang Adiwiyata yang terbaru, namun demikian apabila dilakukan penilaian lapangan, SMPN 3 Sintang sudah memenuhi syarat menjadi Sekolah Adiwiyata namun masih kurang dalam hal konservasi air dan konservasi energi yang juga memerlukan dana dalam pelaksanaannya.

SMPN 3 Sintang memiliki komitmen yang tinggi dalam pengelolaan lingkungan hidup di sekolah. Hal ini disampaikan oleh Kepala SMPN 3 Sintang yang menyatakan bahwa terlepas mengikuti program Adiwiyata atau tidak, lingkungan sekolah akan tetap dijaga agar menjadi tempat yang nyaman untuk melakukan proses pembelajaran. SMPN 3 Sintang berkomitmen untuk selalu menyesuaikan kondisi di sekolah, baik dalam bentuk kebijakan, kurikulum, kegiatan maupun sarana-prasarana yang terstandar sesuai dengan peraturan yang ada dan akan tetap menjaga kelestarian lingkungan sekolah dengan mengedepankan tumbuhan lokal yang bermanfaat dan mudah didapat.

\section{SIMPULAN}

Program Sekolah Adiwiyata di SMPN 3 Sintang tetap dapat terlaksana walaupun dalam kondisi yang kurang ideal. Penerapan Program Sekolah Adiwiyata selama masa Pandemi di SMPN 3 Sintang lebih banyak meneruskan dari program-program yang telah di susun sejak tahun 2016.

Ciri utama sekolah Adiwiyata di SMPN 3 Sintang adalah dengan penanaman tumbuhan lokal di lingkungan sekolah dengan menyesuaikan dengan kontur alam yang ada. Penerapan Sekolah Adiwiyata di SMPN 3 Sintang saat ini masih merujuk pada peraturan berdasarkan Permen LH No. 5 Tahun 2013 tentang Pedoman Pelaksanaan Program Adiwiyata walaupun peraturan ini kemudian sudah direvisi dengan Permen LHK No. 53 Tahun 2019 tentang Penghargaan Adiwiyata. Namun demikian, dampak pandemi yang menyebabkan kondisi Kesehatan dan keuangan yang tidak seperti biasanya menyebabkan saat ini program adiwiyata masih menggunakan pedoman tahun 2013 yang mana masih dirasa relevan dengan kondisi saat ini. SMPN 3 Sintang secara konsisten memiliki komitmen untuk menjaga lingkungannya terlepas dari mengikuti atau tidak mengikuti program sekolah Adiwiyata karena menggangap lingkungan yang baik akan menimbulkan suasana belajar yang nyaman. 


\section{DAFTAR RUJUKAN}

Aksiadi, R., Gumilar, A. 2020. Studi Gaya Kepemimpinan Kepala Sekolah dalam Mengelola Sekolah Adiwiyata di SMPS Ehipassiko School BSD Kota Tanggerang Selatan. Jurnal Manajemen Bisnis, 9 (1) : 31-42.

Anonim. 2020. Perjanjian Kinerja Tahun 2019 Dinas Lingkungan Hidup Kabupaten Sintang. http://sintang.go.id/wpcontent/uploads/2020/10/PK-

2019.pdf. Tanggal Akses 16 September 2021.

Carter, N., Bryant-Lukosius, D., Di Censo, A., Blythe, J., Neville, A.J. (2014). The use of triangulation in qualitative research. Oncology Nursing Forum 41(5): 5455477. doi: 10.1188/14.ONF.545-547.

Intan, T., Hasanah, F., Wardiani, S.R., Handayani, V.T. 2021. Peningkatan Kualitas Hidup di Masa Pandemi Covid-19 dengan Penerapan Pola Hidup Sehat. Jurnal Pengabdian Kepada Masyarakat Royal , 4 (1) : 27$32 . \quad$ DOI: https://doi.org/10.33330/jurdimas.v4i1 .834

Rai, P.K., Singh, J.S. 2020. Invasive alien plant species : Their impact on environment, ecosystem services and human health. Ecological Indicators, 111 (2020) : 120.

https://doi.org/10.1016/j.ecolind.2019. $\underline{106020}$

Setiawan, H., Afriani, R., Dhae, M.D. 2019. Building the framework of local Adiwiyata schools in Sintang District, West Kalimantan Province. JPBI (Jurnal Pendidikan Biologi Indonesia), 5(3), 471-480. doi: https://doi.org/10.22219/jpbi.v5i3.876 1

Setiawan, H. 2021. Artikel Ilmiah Dalam Konteks Manajemen Lingkungan Sekolah : Program Sekolah Adiwiyata Sebagai Solusi Pengelolaan Lingkungan Sekolah Pada Masa Pandemi Covid-19. Edumedia : Jurnal Keguruan dan Ilmu
Pendidikan, Volume 5. Nomor 1, Mei 2021, hlm . $27-32$.

Sugianto, S., Nurkolis, N., Egar, N. 2019. Manajemen Sekolah Adiwiyata di SMK Negeri 1 Adiwerna Kabupaten Tegal. Jurnal Manajemen Pendidikan (JMP), 8 (1) : 22-34.

Sumarni, E., Setiandi, A. E., \& Sunandar, A. (2020). Profile of conceptual photosynthesis and creative thinking: Study of 7th-grade students. Biosfer: Jurnal Pendidikan Biologi, 13(2), 250265.

https://doi.org/10.21009/biosferjpb.v1 $3 n 2.250-265$. 